\title{
Erratum to: Management Strategies for Clopidogrel Hypersensitivity
}

\author{
Craig J. Beavers ${ }^{1,2}$ (1) Nicolas W. Carris ${ }^{3} \cdot$ Kathryn M. Ruf $^{4}$
}

Published online: 29 April 2016

(C) Springer International Publishing Switzerland 2016

Erratum to: Drugs (2015) 75:999-1007

DOI 10.1007/s40265-015-0414-x

\section{Page 1002, Table 1 Clopidogrel desensitization protocol.}

First row in the Volume column, which previously read:

$0.05 \mathrm{ml}$

Should read:

$0.01 \mathrm{ml}$

The online version of the original article can be found under doi:10.1007/s40265-015-0414-x.

Craig J. Beavers

craig.beaverspharmd@gmail.com

1 Cardiovascular Clinical Pharmacy, TriStar Centennial

Medical Center, University of Tennessee College of

Pharmacy, 3200 Patterson Street, Nashville, TN 37203, USA

2 University of Tennessee College of Pharmacy, Nashville, TN, USA

3 Department of Pharmacotherapy and Translational Research and Community Health and Family Medicine, University of Florida College of Pharmacy and Medicine, Gainesville, FL, USA

4 Department of Pharmacy, Jewish Hospital-KentuckyOne Health, Louisville, KY, USA 